\title{
Banco palmas e o microcrédito: um exemplo de sucesso
}

\section{Banco palmas and microcredit: an example of success}

DOI: $10.46814 / \operatorname{lajdv} 3 n 4-026$

Recebimento dos originais: 01/05/2021

Aceitação para publicação: 31/06/2021

\section{Harine Matos Maciel}

Doutora em Desenvolvimento e Meio Ambiente (Universidade Federal do Ceará - UFC), Professora do Instituto Federal do Ceará (Campus Baturité - IFCE), Endereco: Avenida Ouvidor Vitoriano Soares Barbosa Sanhara, sem numero, Cep 62760000, Baturité, Ceará, Brasil E-mail: harine@ifce.edu.br

\section{Jair do Amaral Filho}

Pos Doutor em Ciencias Economicas pela Universite de Paris XIII e Universite Sorbonne Nouvelle IHEAL, Professor da Universidade Federal do Ceará (UFC), Endereco: Avenida da Universidade, 2431, Benfica, 60020-180, Fortaleza, Ceará, Brasil

E-mail: amarelojair@hotmail.com

\section{Wlisses Matos Maciel}

Doutor em Irrigação e Drenagem (Universidade Estadual Paulista - UNESP), Professor do Instituto Federal do Ceará (Campus Umirim - IFCE), Rua Carlos Antonio Sales, sem numero, Floresta, 62660000, Umirim, Ceará, Brasil

E-mail: wlissesmatos@yahoo.com.br

\section{RESUMO}

Este trabalho propõe-se a apresentar o microcrédito como instrumento de desenvolvimento econômico e social na perspectiva de economia solidária. O Banco Palmas é um exemplo de um sistema financeiro solidário criado, em 1988, pela Associação dos Moradores do Conjunto Palmeira. O objetivo do banco é proporcionar o desenvolvimento local e solidário do Conjunto Palmeira, através do microcrédito e programas complementares como a escola de capacitação, incubadora para mulheres em situação de risco, laboratório de agricultura urbana, moeda própria que circula nos comércios do bairro, sistemas de feiras com os produtores locais e uma loja solidária. A metodologia adotada foi um estudo de caso do Banco Palmas através de uma pesquisa documental e pesquisa bibliográfica. Dessa forma, o Banco Palmas mostra que é possível a realização de projetos de desenvolvimento popular e solidário autosustentáveis, por meio do microcrédito, que estimula o consumo e a produção dentro do próprio bairro, em uma perspectiva de desenvolvimento local.

Palavras-Chave: Microcrédito, Economia Solidária, Desenvolvimento Socioeconômico.

\begin{abstract}
This paper proposes to present microcredit as an instrument of economic and social development from the perspective of solidarity economy. Banco Palmas is an example of a financial solidarity system created in 1988 by the Residents Association of Conjunto Palmeira. The objective of the bank is to provide local development and solidarity in Conjunto Palmeira through micro-credit and complementary programs such as a training school, an incubator for women at risk, an urban agriculture laboratory, its own currency that circulates in the neighborhood stores, fair systems with local producers and a solidarity store. The methodology adopted was a case study of Banco Palmas through
\end{abstract}


a documentary and bibliographical research. In this way, Banco Palmas shows that it is possible to carry out self-sustainable popular and solidary development projects, through microcredit, which stimulates consumption and production within the neighborhood itself, in a perspective of local development.

Keywords: Microcredit, Solidarity Economy, Socioeconomic Development.

\section{INTRODUÇÃO}

As dificuldades sócio-econômicas que vêm enfrentando a população brasileira, como o aumento do desemprego, fez com que as pessoas pobres e excluídas do mercado formal de trabalho passassem a utilizar as atividades informais como alternativa para gerar ocupação e renda, e também reduzir a exclusão social.

Experiências no mundo inteiro comprovam que o acesso ao crédito por atividades formais e informais promove o fortalecimento econômico dos empreendimentos e propicia a criação de novos postos de trabalho. O microcrédito em si não é só emprestar dinheiro, como afirma Muhammad Yunus, do Grameen Bank, "é muito mais que entregar e receber de volta, é também mudança social".

As atividades informais e microempresas são inibidas a terem acesso ao crédito tradicional, pois possuem dificuldades para comprovar renda, ter as garantias solicitadas e as taxas de juros são altas, tornando esses segmentos alvo de organizações de microfinanças.

O crédito ágil, oportuno e compatível com as necessidades de seus tomadores é um importante instrumento para o desenvolvimento econômico e social, pois gera oportunidades de crescimento, ocupação e renda. O microcrédito também representa a oportunidade de potencializar o desenvolvimento dos pequenos negócios.

De acordo com o Centro de Estudos em Microfinanças da Fundação Getúlio Vargas (SP), o conceito de microfinanças está relacionado à oferta de serviços financeiros para população de baixa renda, geralmente excluída do sistema financeiro tradicional. Já o microcrédito é a concessão do crédito produtivo para essa população de baixa renda e tem sido uma importante ferramenta de inclusão social em diversos países.

A grande vantagem do microcrédito em seu aspecto de política social é que ele gera incentivos para que seu cliente se envolva em atividades produtivas para poder pagar sua dívida o que fará com que ele tenha capacidade de aumentar a sua renda. Além disso, o microcrédito não é somente uma política social, mas, principalmente, uma política de desenvolvimento econômico, podendo gerar aumentos na produtividade, lucro e estabilidade no setor das microempresas (NERI; MEDRADO, 2005). 
O Banco Grameen de Bangladesh, criado em 1976 pelo professor de economia Muhammad Yunus, é considerado o principal marco referencial na história do microcrédito mundial. O professor Yunus com recursos próprios e com a ajuda de seus alunos, iniciou a concessão experimental de créditos a pessoas pobres para serem utilizados em atividades produtivas.

A experiência pioneira de microcrédito no Brasil ocorreu no contexto das atividades da União Nordestina de Assistência a Pequenas Organizações - UNO, entidade criada em 1973 nas cidades de Recife e Salvador por uma organização não governamental formada por entidades empresariais e bancos em conjunto com a organização não governamental norte americana Acción, que ajudou a disseminar o microcrédito na América Latina. De acordo com Amaral (2005) o objetivo da UNO era apoiar micro e pequenos empreendimentos da região Nordeste, através de financiamento, capacitação gerencial, apoio à comercialização e estímulo à formação de cooperativas e associações de microprodutores.

O objetivo deste trabalho foi apresentar a experiência exitosa do Banco Palmas que consiste em um sistema integrado de microcrédito que organiza e articula os moradores do Conjunto Palmeira, localizado em Fortaleza-Ce, para produzirem e consumirem no próprio bairro

\section{BREVE HISTÓRICO DO MICROCRÉDITO}

Segundo Caldas (2003, p.3) "um sistema de microfinanças pode prover os cidadãos de diversos serviços financeiros, dentre os quais empréstimos, poupança e seguros". A expressão Microfinanças significa o fornecimento de empréstimos, poupanças e outros serviços financeiros especializados para pessoas carentes. Dentro das Microfinanças os principais agentes são conhecidos por Instituições de Microfinanças (IMF). De acordo com Ledgerwood (1999) as IMFs são organizações que oferecem serviços financeiros para pessoas de baixa renda. Também se enquadram no conceito de IMFs as Sociedades que realizam operações de Crédito aos Microempreendedores.

O conceito de microfinanças incorpora e amplia o conceito de microcrédito, na medida que envolve o oferecimento de outros produtos financeiros, além do crédito, tais como: poupança e aplicações financeiras, seguros, etc. Da mesma forma que o microcrédito, esses outros produtos são desenhados de forma a adequar-se às necessidades e demandas das atividades de micro e pequeno porte e de empreendedores de baixa renda (AMARAL, 2005).

O termo microcrédito encontra diferentes definições, para Gulli (1998) apud Neri e Medrado (2005) ele consiste em serviços financeiros de pequena escala, isto é, que envolvam valores baixos, enquanto que Schreiner (2001) apud Neri e Medrado (2005) não define o termo pelo valor emprestado, mas sim como o crédito concedido a pessoas de baixa renda. 
O microcrédito é a concessão de empréstimos de pequeno valor no contexto das microfinanças. Segundo o Serviço Brasileiro de Apoio às Micro e Pequenas Empresas (SEBRAE, 2005) para a legislação brasileira o microcrédito: "São empréstimos de pequeno valor para pessoas e empresas com fins empresariais ou profissionais".

As principais características dos programas bem sucedidos de microcrédito segundo Rhyne e Holt (1994) são: a criação de grupos de pessoas que tomam emprestado juntas e se responsabilizam conjuntamente pelo pagamento das dívidas; o contato direto dos agentes do banco com a realidade e ambiente dos clientes; empréstimos de baixos valores e progressivos de acordo com a inadimplência do cliente; a flexibilidade das formas e datas dos pagamentos frente a choques exógenos; e juros não subsidiados; e não subsidiar os empréstimos ou ter uma mentalidade de perdoá-los

As principais características do microcrédito são:

$\checkmark$ É um serviço fornecido por uma instituição que procura atender a um segmento específico, mas que pretende atuar de acordo com as regras de mercado;

$\checkmark$ O crédito é concedido com um mínimo de burocracia, não exigindo muito tempo de espera, nem muitos documentos, nem um projeto;

$\checkmark$ Deve ser uma instituição auto-sustentada e estar presente em segmentos onde a atividade seja financeiramente viável;

$\checkmark$ Deve ser implementado em áreas que apresentem um potencial mínimo de atendimento, de forma a gerar receita que supere os custos operacionais e recupere os investimentos iniciais (SILVEIRA FILHO, 2005).

O sistema de microcrédito possui determinadas características que o permitem financiar agentes que não reúnem as condições mínimas para fazer empréstimos junto ao sistema bancário formal. Lembrando que esse sistema é especializado para microempresas e pequenos empreendimentos informais.

A concessão de crédito a empreendedores de baixa renda, que não têm garantias reais, tem sido atendida pelo microcrédito de duas maneiras. A primeira é o aval solidário ou fiança solidária, que consiste na reunião de três a cinco pessoas com pequenos negócios e necessidades de crédito, que confiam uma nas outras para formar um Grupo Solidário, com o objetivo de assumir as responsabilidades pelos créditos de todos os grupos. Já para os que não querem participar do Grupo Solidário há uma outra opção que é a apresentação de um avalista ou fiador que preencha condições estabelecidas pela instituição de microcrédito.

É fundamental que o microcrédito seja concedido de forma assistida, o que é feito pelo Agente de Crédito. A postura do Agente de Crédito, suas atitudes, linguagem e abordagem devem levar aos pequenos empreendedores as informações e orientações essenciais para o êxito do negócio. 
O Agente de Crédito é o elo entre a instituição de microcrédito e o tomador do empréstimo, sendo o responsável pelo estabelecimento de uma relação profissional de confiança. Também está envolvido em todo o processo de liberação e recebimento do crédito. Diferentemente das práticas bancárias tradicionais, o Agente de Crédito vai até o cliente e não o contrário.

\section{O CASO DO BANCO PALMAS}

A comunidade do Conjunto Palmeira é um exemplo de uma história de luta em busca da superação da pobreza. Diante desta realidade tem-se como objetivo da pesquisa um estudo de caso do Banco Palmas que consiste em um sistema integrado de microcréditos que organiza e articula os moradores do Conjunto Palmeira. O Banco Palmas é um programa que foi criado e é totalmente administrado pela Associação de Moradores do conjunto, dentro da lógica da socioeconomia solidária, indo muito além do simples ato de concessão do crédito.

O Conjunto Palmeira, que fazia parte do Bairro Jangurussu, mas em dezembro de 2007 tornouse um bairro, possui aproximadamente 32 mil habitantes e situa-se em Fortaleza no Estado do Ceará, Nordeste do Brasil. Em 1973, no Governo de César Cals, famílias faveladas provenientes do Lagamar, Aldeota, Poço da Draga, Arraial Moura Brasil, Morro das Placas e Verdes Mares foram despejadas e encaminhadas para o loteamento no Conjunto Palmeira com o objetivo de urbanizar a Praia de Iracema.

As famílias eram colocadas em cima de um caminhão, recebiam uma lona e eram despejadas no meio do mato e da lama do Palmeiras. Durante muitos anos o conjunto ficou conhecido como o bairro dos índios, porque moravam no meio do mato. O local contava com uma enorme quantidade de palmeiras, daí o nome Palmeiras, que foram arrancadas para liberar o espaço para as construções das moradias. Os moradores sem nenhuma ajuda foram construindo espontaneamente seus barracos, dando origem a uma grande favela, não havia rede de saneamento básico, água tratada, energia elétrica, escola ou qualquer outro serviço público.

Em 1977 a população do Conjunto Palmeira se mobilizou para lutar pela melhoria da saúde no bairro. Já em 1978 os moradores conquistaram a construção de uma Escola de 1º Grau Audaci Barbosa, o Centro Social Urbano (CSU) e o Posto de Saúde Pedro Sampaio. Assim os moradores começaram a perceber que juntos poderiam fazer muito pelo conjunto em que viviam. No ano de 1979 teve início a luta da comunidade pelos serviçoes básicos como água tratada e energia elétrica. Em 1980 houve a consolidação da ASMOCONP (Associação dos Moradores do Conjunto Palmeira) que uniu algumas famílias moradoras do bairro para iniciar uma série de reivindicações até conseguir esgoto, água, luz, asfalto e escolas. A situação do Conjunto Palmeira em 1984 ainda era de miséria, lama, lixo, falta de serviços públicos e violência. Um dos maiores problemas do conjunto era a falta de água encanada. A água no conjunto era trazida por caminhões pipas para abastecer vasilhames que serviriam para o 
atendimento das necessidades das famílias, mas a quantidade era insuficiente. Em 1988, em meio a uma intensa mobilização popular, com duas passeatas à Companhia de Água e Esgoto do Ceará (CAGECE) e uma grande concentração em frente à sede do Governo do Estado, o então governador era o Tasso Jereissati, os moradores deram um ultimato: ou se implantava a rede de água do conjunto ou explodiriam a tubulação da dutora que abastecia a cidade de Fortaleza e que passava sob a área do Conjunto Palmeiras. Deram um prazo de quinze dias para o início das obras pelo Governo e foi isso o que aconteceu. Em 1991 as lideranças comunitárias organizaram o seminário "Habitando o Inabitável”, que se torna um marco na história do conjunto, do seminário saíram as idéias para a criação da União das Associações e Grupos Organizados do Conjunto Palmeiras (UAGOCONP) e a definição de um plano estratégico para urbanizar o bairro nos próximos dez anos. Em 1997, foi realizado um encontro para avaliar o Seminário "Habitando o Inabitável”, que ocorreu em 1991, e chegou-se à conclusão de que o bairro já estava urbanizado, mas a pobreza econômica dos moradores tinha aumentado. O bairro sofria com o desemprego, pouca circulação local de renda e pobreza.

Com o objetivo de conhecer a realidade econômica do conjunto a Associação de Moradores realizou uma pesquisa e chegou à conclusão que o comércio local não se desenvolvia porque o dinheiro não circulava no próprio conjunto, pois os próprios moradores preferiam comprar em outros lugares devido a facilidades no ato da compra. Dessa forma, os pequenos negócios do conjunto faliam, desempregando a população local.

O desafio era como em meio à pobreza fazer produzir, gerar consumo e circular as economias na própria comunidade, pois o dinheiro que circulava ali era oriundo do comércio, serviços e aposentadorias. A dificuldade era como segurar esse dinheiro dentro da própria comunidade, mas foi nesse contexto que entrou a idéia do Banco Palmas, um banco comunitário.

No ano de 1997, num seminário de avaliação da comunidade, organizado e realizado pela Associação de Moradores, foi criado um projeto de geração de trabalho para a comunidade. Esse projeto foi inaugurado em janeiro de 1998 e recebeu o nome de Banco Palmas. Em janeiro de 1998 o Banco Palmas foi inaugurado e implantou uma rede de solidariedade entre os moradores. O objetivo do banco é garantir microcrédito para as famílias, a juros baixos, sem exigência de consultas cadastrais, comprovação de renda ou fiador. Os vizinhos passam a dar a garantia ao tomador do crédito, assumindo se a pessoa é responsável ou não.

O objetivo inicial do Banco foi o combate à pobreza com desenvolvimento local e mobilização social. Segundo Melo (2003) o Banco pretendia aproveitar as potencialidades do bairro, tendo a solidariedade como princípio, articular o diálogo entre governo local e sociedade civil e desenvolver uma estrutura financeira de créditos para os mais pobres, como alternativa de superação da pobreza. 
Inicialmente a comunidade do Conjunto Palmeira enfrentou problemas na implementação do Banco Palmas, como já se esperava, pois o Banco era uma iniciativa pioneira no Estado do Ceará e na própria região Nordeste do país. Conforme Melo (2003) dentre as maiores dificuldades foram o convencimento dos parceiros quanto à capacidade da Associação para fazer a gestão do Banco, obtenção de recursos iniciais, inexperiência da equipe em gerenciar uma estrutura financeira, dificuldade dos sócios em conviver com uma proposta econômica (créditos, juros, cobranças) dentro de um espaço de ações comunitárias e problemas de segurança para os recursos do banco, devido os assaltos constantes na região.

O Banco de início foi financiado por um empréstimo de cerca de mil dólares, concedido pela ONG CEARAH Periferia (ONG), além de treinamentos, tendo suas instalações numa pequena sala localizada na sede da Associação de Moradores e começando com apenas dez clientes. Alguns meses depois recebeu recursos a fundo perdido da cooperação internacional da OXFAM e da GTZPRORENDA. Atualmente, o Banco recebe apoio financeiro da cooperação internacional e de fontes públicas locais. Os recursos arrecadados através dos juros, que são poucos, também ajudam a pagar as despesas do Banco.

O Banco Palmas, assim, surge como um sistema integrado que organiza e articula os moradores do Conjunto Palmeira para produzirem e consumirem no próprio bairro, articulados em rede. É um programa de desenvolvimento local que vai além da concessão de microcrédito, busca a capacitação e empoderamento dos moradores, despertando a sensibilidade para a solidariedade e a colaboração, enquanto estratégia de um modelo de desenvolvimento justo e sustentável. Dessa forma, busca a autonomia e emancipação dos sujeitos envolvidos (OLIVEIRA, 2007).

O Banco Palmas é um Banco Comunitário que oferece serviços financeiros solidários de natureza associativa e comunitária. $\mathrm{O}$ banco é de propriedade da comunidade. $\mathrm{O}$ banco funciona dentro da sede da Associação, mas tem uma coordenação própria. O Banco Palmas presta contas com a comunidade mensalmente através do Fórum de Economia Local (FECOL), criado em março de 2007, abordando também questões do Conjunto e ouvindo sugestões da comunidade, o FECOL faz a controladoria Social do Banco Palmas. O empréstimo do banco pode ou não ser solidário. O Palmas apenas orienta as pessoas que tenham atividades afins que se juntem para formar um grupo e produzir coletivamente. O valor do empréstimo vai de $\mathrm{R} \$ 300,00$ a $\mathrm{R} \$ 1.000$, podendo ser devolvido em até seis meses, $80 \%$ dos clientes são mulheres, isso ocorreu espontaneamente, pois estas são mais empreendedoras, desafiantes e corajosas.

A cobrança é feita através dos analistas de crédito que utilizam fortemente o aval de vizinhança, que consiste em perguntar para os vizinhos se a pessoa é honesta, se trabalha, pois para entrar para o sistema é dispensado o fiador, consulta ao SERASA, enfim tudo que o meio tradicional exige. A 
maioria dos moradores do Conjunto Palmeira está com seus nomes fichados em um desses sistemas. A partir do momento que o cliente é aceito no banco ele passa a ser acompanhado por toda a rede de solidariedade. Esse controle social fiscaliza as ações do banco e dos seus empreendedores, ajudando, inclusive a inadimplência do Palmas ficar sempre na casa de 1 a $3 \%$.

O banco trabalha com uma política de créditos evolutivos e juros evolutivos, para garantir a distribuição de renda. Quem tem mais, paga mais juros para subsidiar o empréstimo de quem tem menos.

O Banco Palmas é completamente sustentável, pois tem hoje mais de 3 mil famílias na carteira ativa de crédito, segundo dados do boletim de atividade do ano de 2013.

Os financiamentos oferecidos pelo Banco Palmas são cinco:

1) Microcrédito para produção, comércio ou serviço Microcrédito cedido para quem não pode acessar as fontes de financiamento oficial por causa da burocracia e das exigências relativas a fiador, nível de renda e outras normas bancárias;

2) Palmacard é um cartão desenvolvido para solucionar o problema da falta de poder de compra do bairro. Através do PalmaCard o Banco Palmas oferece crédito ao consumo a particulares do bairro. Este funciona como um cartão de crédito, no qual os moradores podem comprar nas empresas cadastradas e pagar após 30 dias ao Banco Comunitário. Fazendo assim o círculo de compra e venda dentro do próprio bairro.

O Palmacard ajuda a resolver problemas emergenciais das famílias como a compra de remédios, gás de cozinha e alimentos. Assim estimula o comércio local e mostra para os moradores que ao consumir produtos e serviços do bairro estão ajudando a distribuir a renda, gerando riquezas e melhorando a qualidade de vida na comunidade. Os comerciantes beneficiados pelo sistema se encontram em assembléia mensal para avaliarem o funcionamento do cartão, apresentar sugestões e contribuírem com sua participação e trabalho voluntário para as ações sociais da associação como limpeza, preservação de praças, acompanhamento às escolas e postos de saúde, entre outros.

3) Microcrédito para Mulheres, é através dessa linha de crédito específica, o Palmas tem financiado mulheres empreendedoras do conjunto, principalmente as que se encontram em situação de risco pessoal e social como mães solteiras na faixa etária de 18 a 65 anos.

4) PalmaCasa é uma linha de crédito para pequenas reformas de moradia, objetivando a melhoria nas condições de produção. As famílias fazem um orçamento em um depósito de construção do conjunto e recebem uma autorização do banco para receber o material. O dono do depósito recebe o dinheiro do banco e o beneficiado tem até 6 meses para pagar com juros de 1,5\% ao mês, de acordo com o Banco Palmas. 
5) Agricultura Urbana permite que as famílias tomem um pequeno empréstimo no banco, no valor máximo de $\mathrm{R} \$ 100,00$ e paguem em até 10 meses. As atividades serão desenvolvidas nos quintais das residências podendo ser uma horta, plantas medicinais ou criação de galinha caipira.

A moeda local é o Palma que foi criado para circular a riqueza dentro do Conjunto Palmeira. Cada Palma equivale a $\mathrm{R} \$ 1$. Os moradores conseguem a moeda com o próprio trabalho ou com empréstimo do banco.

A finalidade dessa moeda social é estimular o consumo de bens e serviços produzidos pela própria comunidade. O diferencial do Palma é que o crédito oferecido pelos bancos comunitários em moeda oficial funcionam com taxas de juros de $0,5 \%$ a $3 \%$, abaixo das praticadas pelo mercado.

No início a criação do Palma trouxe um grande problema para a comunidade, pois o Banco Central em 2003 acusou o Banco Palmas de crime contra a União por emissão indevida de moeda. No entanto, após a prestação de depoimentos por parte dos participantes do sistema, foi reconhecido o caráter social do projeto e concluiu-se que o Palma não concorria com o Real, pois equivalem a recebíveis como vale-transporte, não sendo válidas para pagamento de impostos. O Banco Central também recomenda que a aparência das notas se difira claramente do aspecto da moeda oficial.

O trabalho desenvolvido por Menezes (2007) sobre a importância das moedas locais, o estudo de caso do Banco Bem em Vitória/ES, elenca as vantagens percebidas na existência de uma moeda própria do local. As vantagens citadas no presente estudo da moeda local são os descontos, favorecimento da economia local, melhoria da qualidade de vida e melhoria do relacionamento com a comunidade. O principal motivo apontado foi à existência de descontos nas compras com a moeda local. Com base no que foi concluído no trabalho de Menezes (2007), pode-se dizer que todos os motivos elencados são de extrema importância para a moeda local, pois esta moeda auxilia os moradores a aumentarem seu poder de compra, uma maior integração na comunidade, enfim traz uma melhoria de vida para a população assistida.

\section{CONSIDERAÇÕES FINAIS}

Esse trabalho analisou o microcrédito como instrumento de desenvolvimento econômico e social. Mostrou-se que o microcrédito é capaz de criar bifurcações diversas como a criação do Banco Palmas, um exemplo de Economia Solidária.

A criação do banco aumentou a renda das famílias devido o acesso ao crédito. O Banco Palmas criou o Palma, uma moeda social com a qual os moradores compram, vendem e movimentam a economia local. Os moradores conseguem a moeda com o próprio trabalho ou com empréstimos do banco. A população compra no bairro para ajudar os próprios moradores, pois a união dos moradores traz mais desenvolvimento, pois gera emprego e renda, melhorando assim a vida da população local. 
A estratégia utilizada pela comunidade do Conjunto Palmeira demonstra que a união da população em busca de melhorias na qualidade de vida pode exercitar sua cidadania e serem capazes de produzir transformações em suas realidades, pois o poder de mobilização de comunidades carentes é muito mais forte do que a simples aplicação de projetos. O Conjunto Palmeira cresce a cada dia e sua experiência está sendo levada para todo o país, pois seu objetivo de romper o ciclo da pobreza e melhorar a renda da população com projetos de desenvolvimento social local ajudam a promover o desenvolvimento humano. Dada a relevância do assunto seria interessante que realizassem estudos de caso comparativos entre Bancos Comunitários, inclusive em nível internacional, para acompanhar como essas experiências modificam a vida dos beneficiados. 


\section{REFERÊNCIAS BIBLIOGRÁFICAS}

AMARAL, Carlos. Microfinanças e Produção Sustentável nos Ambientes Costeiro e Marinho no Brasil: Possibilidades e Desafios. Estudo realizado a partir de solicitação da Agência Costeira, Fevereiro de 2005, 61p.

BANCO CENTRAL DO BRASIL. Diferença entre Microcrédito e as Microfinanças. Disponível em http://www,bacen.gov.br. Acesso em maio de 2011.

BANCO PALMAS. História do Conjunto Palmeira e do Banco Palmas. Disponível em http://www.bancopalmas.org.br. Acesso em julho de 2011.

BANCO PALMAS. Ações do Banco Palmas. Disponível em http://www.bancopalmas.org.br. Acesso em julho de 2011.

CALDAS, Eduardo de Lima. Da experiência do Microcrédito à Microfinança. Artigo publicado na Revista Diálogo Econômico Local nº 1, julho de 2003.

FUNDAÇÃO GETÚliO VARGAS (FGV). Centro de Estudos em Microfinanças (CEMF). Disponível em http://www.eaesp.fgvsp.br. Acesso em março de 2011.

INSTITUTO BANCO PALMAS. Dados Financeiros, 2013. Disponível em Instituto Banco Palmas | Inova. Acesso em julho de 2021.

LEDGERWOOD, Joanna. Microfinance handbook: an institutional and financial perspective. Washington,D.C.: World Bank, 1999.

MELO, Liana. Aceita palmas? No país do real, os mais pobres driblam a falta de dinheiro com a criação de moedas próprias. Istoé Online, 2003. Disponível em http://www.terra.com.br. Acesso em julho de 2011.

MENEZES, Melissa Silva. Moedas Locais: uma investigação exploratória sobre seus potenciais como alternativa à exclusão financeira a partir do caso do Banco Bem em Vitória/ES. Dissertação de Mestrado, Belo Horizonte, Cedeplar 2007.

NERI, Marcelo; MEDRADO, André Luiz. Experimentando Microcrédito: Uma Análise do Impacto do CrediAMIGO sobre Acesso a Crédito. Ensaios Econômicos. Escola de Pós-Graduação em Economia da Fundação Getúlio Vargas. Dezembro de 2005.

OLIVEIRA, Simone Helena dos Santos. Conjunto Palmeira: sua história no enfrentamento da pobreza e na busca do desenvolvimento humano. Revista Latino-Americana de Enfermagem. Ribeirão Preto, v.15, 2007.

RHYNE, E.; HOLT, S. Women in Finance and Enterprise Development. Education and Social Police Discussion Paper 40, World Bank, Washington, D.C. 1994.

SEBRAE. Microcrédito e OSCIP, 2005. Disponível em http://www.sebrae.com.br. Acesso em julho de 2011. 
SILVEIRA FILHO, Jaime Albuquerque. Microcrédito na Região Metropolitana do Recife: Experiência Empreendedora do CEAPE. Dissertação de Mestrado, Recife - Pernambuco, setembro/2005.

YUNUS, Muhammad. O Banqueiro dos Pobres. Londres: Public Affairs, 1999, 343p 